\title{
A nosocomial outbreak of 2009 pandemic influenza A (H1N1) in a paediatric oncology ward in Italy, October - November 2009
}

M Chironna ${ }^{1}$, S Tafuri ${ }^{1}$, N Santoro ${ }^{2}$, R Prato ${ }^{3}$, M Quarto $^{1}$, C A Germinario (c.germinario@igiene.uniba.it) ${ }^{1}$

1. Department of Biomedical Sciences, Hygiene Section, University of Bari, Apulia Regional Epidemiological Observatory, Bari, Italy

2. Paediatric Unit F.Vecchio, Policlinico General Hospital, Bari, Italy

3. Department of Medical Sciences, Hygiene Section, University of Foggia, Apulia Regional Epidemiological Observatory, Foggia, Italy

Citation style for this article: Chironna M, Tafuri S, Santoro N, Prato R, Quarto M, Germinario CA. A nosocomial outbreak of 2009 pandemic influenza A (H1N1) in a paediatric oncology ward in Italy, October - November 2009. Euro Surveill. 2010;15(1): pii=19454. Available online: http://www.eurosurveillance.org/ViewArticle. aspx?Articleld $=19454$

This article has been published on 7 January 2010

A nosocomial outbreak of 2009 pandemic influenza $A\left(H_{1} N_{1}\right)$, with eight confirmed cases, occurred in a paediatric oncology ward in Italy, in October/November 2009. The fact that one case was infected despite being isolated and without contact to a symptomatic patient, hints towards potential transmission through a health care worker (HCW) and underlines the importance of vaccination of $\mathrm{HCW}$ who are involved in the care of critically ill patients.

\section{Outbreak description}

A nosocomial outbreak of 2009 pandemic influenza $A\left(\mathrm{H}_{1} \mathrm{~N}_{1}\right)$, with eight laboratory confirmed cases, occurred in a paediatric oncology hospital ward in Italy, in October/November 2009.

For the outbreak the following case definition was applied: A suspected case was defined as a person presenting with a history of acute onset of high fever $\left(\geq 38{ }^{\circ} \mathrm{C}\right.$ ) and at least two of the following respiratory symptoms: nasal obstruction, rhinorrhoea, sore throat, cough. This definition did not exclude individuals with negative RT-PCR for 2009 pandemic influenza $A\left(H_{1} N_{1}\right)$ virus. A confirmed case was defined as a suspected case with laboratory-confirmed 2009 pandemic influenza $A\left(\mathrm{H}_{1} \mathrm{~N}_{1}\right)$, as tested by RT-PCR (Real time ready Influenza $A\left(\mathrm{H}_{1} \mathrm{~N}_{1}\right)$, Roche Diagnostics, Mannheim, Germany) $[1,2]$.

Time line of events

During the outbreak, 20 children were hospitalised in the paediatric oncology ward. The first case was reported at the end of October in a child who had been admitted three days earlier for chemotherapy. The child presented with acute onset of fever $\left(38^{\circ} \mathrm{C}\right)$, nasal congestion and cough. The source of influenza infection remains unknown. The parents did not report any contact with a confirmed influenza case in the seven days prior to the onset of symptoms. Three days after the first case, another hospitalised child who had been hospitalised for chemotherapy over two weeks earlier, developed fever and acute respiratory symptoms.

On the day after the second child had developed symptoms, a voluntary association organised a Halloween party for the children hospitalised in the ward. All children participated, except one who was isolated because of severe clinical condition. In addition, an outpatient who came to hospital to receive chemotherapy attended the party. During the festivity all children covered their faces with surgical masks.

Three days after the party, in early November, seven hospitalised children presented with a fever of $\geq 38{ }^{\circ} \mathrm{C}$ and acute respiratory symptoms and on the following day, the isolated child and the outpatient presented an influenza-like syndrome (fever and respiratory symptoms) as well (Figure).

\section{Laboratory investigations}

At onset of fever, pharyngeal swabs were performed on all symptomatic children and tested for 2009 pandemic influenza. The laboratory results were available two days after the last children had become symptomatic and confirmed the diagnosis in eight of the 11 symptomatic children: the two children who had developed influenza symptoms in October, the child in isolation, the outpatient and four of seven who had developed fever in early November. All cases were laboratoryconfirmed by the regional reference laboratory in Bari (Unità Operativa Igiene Policlinico Bari) by real time RT-PCR [2].

The age for the eight confirmed cases ranged from 10 months to 13 years, two children were under one year old, three were between one and five years old, two were between six and 10 years old and one was over 10 years old. All were hospitalised at the same time 
for a period between four and 20 days in the paediatric oncology ward, with the exception of a child who had come to hospital during this period to receive chemotherapeutic infusions as an outpatient. Four of seven hospitalised confirmed cases, had acute lymphocytic leukaemia, two had neuroblastoma and one hepatoblastoma, three were neutropenic at admission and all had been hospitalised for chemotherapy. No patient had had any respiratory symptoms before admission to the hospital or prior to the outbreak.

The median duration of illness was 15 days (range 7-25). The attack rate for all hospitalised cases (suspected and confirmed) was $50 \%$ and for confirmed cases $35 \%$. Three patients presented evidence of secondary pneumonia. One patient had to be admitted to the intensive care unit and was ventilated for 30 days.

\section{Control measures}

When the laboratory results were available, all patients with confirmed 2009 pandemic influenza were treated with $75 \mathrm{mg}$ oseltamivir daily for five days. In addition, they received antibiotic and antifungal prophylaxis for ten days. All symptomatic children were lodged in a separate division of the ward until 48 hours after symptoms had subsided. Contact with other hospitalised children was prohibited and external visits were restricted to a minimum. All health care workers (HCW) used professional protective equipment, such as surgery masks, disposable gowns and gloves until 48 hours after the patients' symptoms had subsided.

\section{Discussion}

Since the start of the pandemic in Italy, this has been the first important cluster of 2009 pandemic influenza in a hospital setting involving patients at high risk of complication. Nosocomial transmission of seasonal influenza is well documented, but there are not many

\section{FIGURE}

Epicurve for 2009 pandemic influenza $\mathrm{A}(\mathrm{H} 1 \mathrm{~N} 1)$ cases in a paediatric oncology ward by onset of symptoms, Italy, October-November 2009 ( $\mathrm{n}=11)$

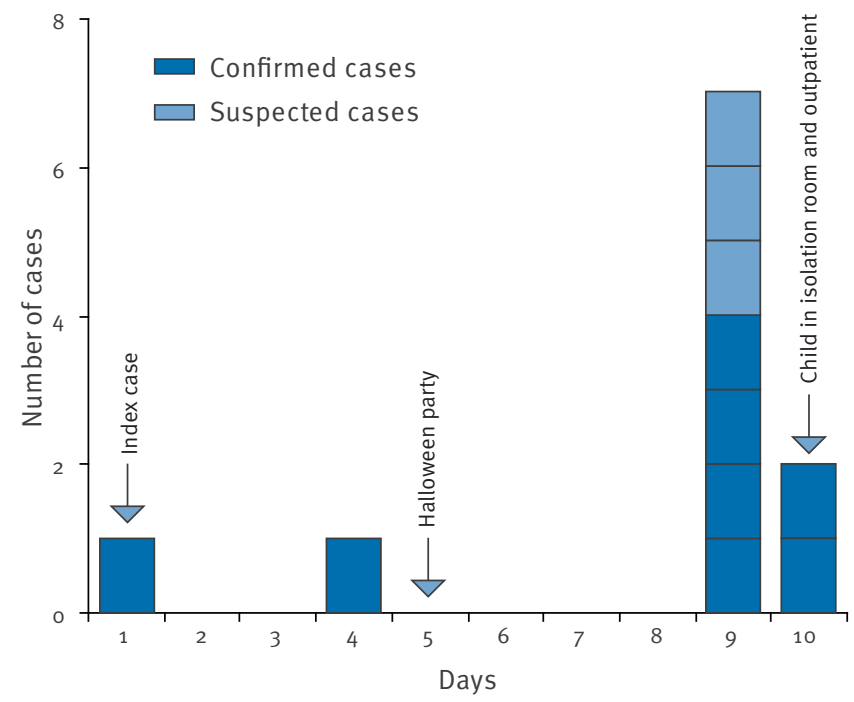

reports about nosocomial outbreaks of 2009 pandemic influenza. In the outbreak described, a case of 2009 pandemic influenza occurred in a strictly isolated patient and we can exclude contact with infected patients. Even if no HCW showed influenza-like symptoms during the outbreak, this hints towards an asymptomatic HCW as potential source of infection. To prevent transmission of pandemic influenza in health care settings, HCW should consider influenza early as differential diagnosis, and a high level of awareness of pandemic influenza diagnosis and appropriate infection control practices should be guaranteed. Fever often occurs in oncology patients due to paraneoplastic syndromes, opportunistic infections or chemotherapy [3-7]. This may lead to a delay in diagnosing influenza and consequently to a late application of control measures including restriction of contacts. In fact two symptomatic children were admitted to the Halloween party because clinicians did not consider the diagnosis of influenza.

Oseltamivir is effective for prevention of complications associated with pandemic influenza in children. It also reduces the duration of influenza on average by 36 hours, with nausea and vomiting as the primary reported adverse effects [8]. The World Health Organization recommends oseltamivir as first-line treatment for 2009 pandemic influenza, with the use of zanamivir only for cases with suspected or confirmed oseltamivir resistance [9]. Oseltamivir is most effective if given within 48 hours of onset of symptoms. In the outbreak presented, oseltamivir was administered only after the laboratory confirmation, several days after the start of symptoms.

Influenza viruses are transmitted through aerosols, large droplets, or direct contact with secretions (or fomites). Occupational health and infection prevention and control should follow the precautionary principle and the recommendations or findings presented in the scientific literature to ensure staff safety during an influenza pandemic. A comprehensive approach to staff safety should be considered when planning for such an event. This includes implementing routine practices and additional precautions in all healthcare institutions, optimal hand hygiene, fit-tested N95 respirators for staff providing direct care to patients, vaccination of all staff when an effective vaccine is available and chemoprophylaxis in the case of influenza A. Patients will be best cared for when HCW are convinced that everything possible is being done to protect their own health as well [10].

The outbreak described, started before the availability of pandemic vaccine in the particular Region. At present, pandemic vaccine is offered to oncology patients, HCW, relatives and carers of high risk patients such as immunocompromised persons [11]. HCW can be an important source of infection for transmission of influenza, seasonal and pandemic, to patients. HCW may be asymptomatic in the incubation period and 
spread the infection especially in close-contact situations [12-14]. Several randomised clinical trials carried out in long-term care facilities have shown that high influenza vaccination coverage in $\mathrm{HCW}$ is associated with reduction in infection rates and decreased mortality for acute respiratory diseases in patients and residents during the winter months $[15,16]$. Vaccination of HCW against 2009 pandemic influenza is an ethic necessity, especially for those who work with immunocompromised patients. In addition, vaccination of $\mathrm{HCW}$ is strongly recommended to avoid interruption of essential care services during an influenza pandemic. Healthcare services are urged to promote activities that increase the uptake of pandemic vaccine of their employees [17-18].

\section{References}

1. Italian Ministry of Health. Circolare del Ministero della Salute n. $0023277 \mathrm{del}$ 20/5/2009. Nuova syndrome influenzale da AH1N1v. [Circular Letter n. 0023277. New AH1N1v Influenza Syndrome. 20/5/2009.]. Italian. Available from: http:// www.nuovainfluenza.ministerosalute.it/nuovainfluenza/ archivioOrdinanzeCircolariNuovalnfluenza.jsp (accessed on 5 January 2009)

2. Panning $M$, Eickmann $M$, Landt $O$, Monazahian $M$, Ölschläger $\mathrm{S}$, Baumgarte $\mathrm{S}$, et al. Detection of influenza $\mathrm{A}\left(\mathrm{H}_{1} \mathrm{~N}_{1}\right)$ v virus by real-time RT-PCR. Euro Surveill. 2009;14(36):pii=19329. Available from: http://www.eurosurveillance.org/ViewArticle. aspx?Articleld=19329

3. Sonis ST, Oster G, Fuchs H, Bellm L, Bradford WZ, Edelsberg J, et al. Oral mucositis and the clinical and economic outcomes of hematopoietic stem-cell transplantation. J Clin Oncol 2001;19(8):2201-5

4. Fratino G, Molinari AC, Parodi S, Longo S, Saracco P, Castagnola $\mathrm{E}$, et al. Central venous catheter-related complications in children with oncological/hematological diseases: an observational study of 418 devices. Ann Oncol. 2005;16(4):648-54

5. Ninin E, Milpied N, Moreau P, Andre-Richet B, Morineau N, Mahe B, et al. Longitudinal study of bacterial, viral, and fungal infections in adult recipients of bone marrow transplants. Clin Infect Dis. 2001;33(1):41-7

6. Barker JN, Hough RE, van Burik JA, DeFor TE, MacMillan ML, O'Brien ML, et al. Serious infections after unrelated donor transplantation in 136 children: impact of stem cell source. Biol Blood Marrow Transplant. 2005;11(5):362-70

7. El-Radhi AS, Patel SP. Temperature measurement in children with cancer: an evaluation. Br J Nurs. 2007;16(21):1313-6

8. Jamieson B, Jain R, Carleton B, Goldman RD. Use of oseltamivir in children. Can Fam Physician. 2009;55(12):1199-201.

9. Antiviral drugs and pandemic $\left(\mathrm{H}_{1} \mathrm{~N}_{1}\right) 2009$ [website on the internet]. Copenhagen: World Health Organization regional Office for Europe. 2009. Available from: http://www.who.int/ csr/disease/swineflu/frequently_asked_questions/antivirals/ en/index.html [accessed 5 January 2010].

10. Devlin HR, Abou-Sweid S, King J. It's not just about the mask. Healthc Pap. 2007;8(1):29-33; discussion 50-5.

11. Italian Ministry of Health. Ordinanza del Ministero del lavoro, della salute e delle politiche sociali - 30 settembre 2009. Misure urgenti in materia di protezione dal virus influenzale $A\left(\mathrm{H}_{1} \mathrm{~N}_{1}\right)$. [Order 30 September 2009. Urgent actions to prevent the $A / H_{1} 1$ pandemic influenza. Italian Office Bulletin n. 234, 8 October 2009] Italian. Available from: http:// www.nuovainfluenza.ministerosalute.it/nuovainfluenza/ archivioOrdinanzeCircolariNuovalnfluenza.jsp (accessed on 5 January 2009)

12. Hofmann F, Ferracin C, Marsh G, Dumas R. Influenza vaccination of healthcare workers: a literature review of attitudes and beliefs. Infection. 2006;34 (3):142-7

13. Burls A, Jordan R, Barton P, Olowokure B, Wake B, Albon E, et al. Vaccinating healthcare workers against influenza to protect the vulnerable-is it a good use of healthcare resources? A systematic review of the evidence and an economic evaluation. Vaccine 2006;24(19):4212-21

14. Bridges CB, Kuehnert MJ, Hall CB. Transmission of influenza: implications for control in health care settings. Clin Infect Dis. 2003;37(8):1094-101
15. Carman WF, Elder AG, Wallace LA, McAulay K, Walzer A, Murray $\mathrm{GD}$, et al. Effects of influenza vaccination of healthcare workers on mortality of elderly people in long-term care: a randomized controlled trial. Lancet. 2000 Jan 8;355(9198):93-7

16. Hayward AC, Harling R, Wetten S, Johnson AM, Munro $\mathrm{S}$, Smedley J, et al. Effectivness of an influenza vaccine programme for care home staff to prevent death, morbidity and health service use among residents: cluster randomised control trial. BMJ 2006;333(7581):1241

17. Italian Ministry of Health. Piano nazionale di preparazione e risposta ad una pandemia influenzale. [National pandemic preparedness and response plan.] Italian. Available from: http://www.governo.it/Governolnforma/Dossier/influenzaA/ piano nazionale.pdf (accessed on 20 November 2009)

18. Zarocostas J. Healthcare workers should get top priority for vaccination against $\mathrm{A} / \mathrm{H}_{1} \mathrm{~N}_{1}$ flu, WHO says. BMJ. 2009;339:b2877 